\title{
Introduction to the 2016 Aortic Symposium Supplement
}

\author{
Joseph S. Coselli, MD, ${ }^{\mathrm{a}}$ and Richard D. Weisel, $\mathrm{MD}^{\mathrm{b}}$
}
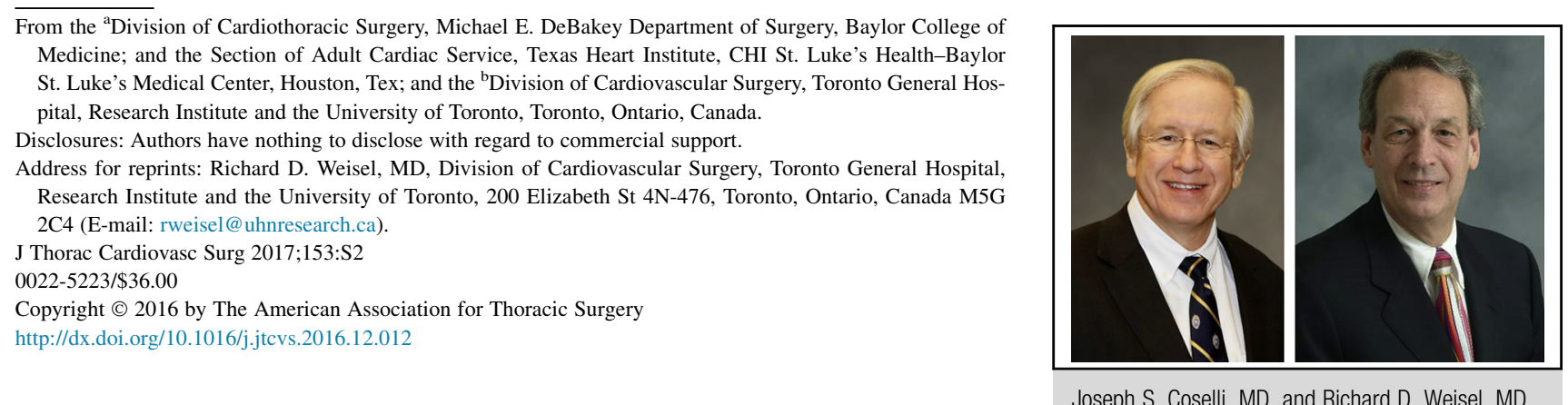

Welcome to the first AATS 2016 Aortic Symposium Supplement. In May 2016, during AATS week, 45 presentations were made during the 2 days of the Symposium. Most of the important topics in aortic surgery were debated and the latest updates were discussed. The Symposium focused on the pathophysiology, diagnosis, and treatment of aortic aneurysms and dissections. The faculty consisted of world leaders in this field who were invited to share their experiences. The best abstracts were selected for presentation. The Aortic Symposium Supplements in the JTCVS provide a lasting reminder of the excellent science and expert experience presented at the Symposium.

Many of the Symposium presentations were submitted to the JTCVS and, after peer review, a number were

accepted. The first collection is published in this supplement. Several presentations from the meeting are also being published in Seminars in Thoracic and Cardiovascular Surgery (the links to those publications are provided below). Later in 2017, the second Aortic Symposium Supplement will be published with additional outstanding contributions.

The supplement provides a broad spectrum of the newest approaches to aortic dissections and aneurysms. Each of the articles is accompanied by an expert commentary to put the new discoveries into perspective.

We hope that you enjoy this new feature in the Journal. Aortic surgeons will find it rewarding. 